\title{
Identification of antioxidant bioactive compounds as potential functional food ingredient from kebar grass (Biophytum petersianum) by metabolomic approach
}

\author{
Aminudin AMINUDIN ${ }^{1,2 *}$ (D), Nuri ANDARWULAN ${ }^{2,3}$, Nurheni Sri PALUPI ${ }^{2,3}$, Raden Iis ARIFIANTINI ${ }^{4}$
}

\begin{abstract}
Kebar grass (Biophytum petersianum) is traditionally believed as a food ingredient to increase the health of the reproductive. The specific bioactive compounds with antioxidant effect in this plant have not been reported before. The objective of this research was to identify the specific bioactive compounds as a source of functional food ingredients of Kebar grass (KG) which have antioxidant activity by using a metabolomic approach. Samples chemical profile (extract and fraction) used HPLC, followed by metabolomic analysis by OPLS. Chosen samples were isolated by TLC and then identified by UHPLC-MS/MS. Specific bioactive compounds were identified from chromatogram with putative identification by MZmine referring to online databases. The metabolomic result obtained ethyl acetate fraction (FEA) as the sample that most contributed to antioxidant activity. FEA identification result showed ten specific bioactive compounds that are thought to contribute to antioxidant agents. Two of the compounds were identified as caffeic acid and cassiaoccidentalin A, while the other eight compounds have not been identified. The finding of cassiaoccidentalin A in KG is a novel finding and can be used as a specific marker for petersianum species of Biophytum genus and as a source of functional food ingredients as antioxidant agents to improve reproductive health.
\end{abstract}

Keywords: Biophytum petersianum; kebar grass; antioxidant; metabolomics; cassioaccidentalin A.

Practical Application: Kebar grass plants can be further developed as a source of functional food ingredients or supplements to improve performance and maintain reproductive health.

\section{Introduction}

Kebar grass (Biophytum petersianum) is a part of the family Oxalidaceae from the genus Biophytum. This plant is endemic to Kebar District, West Papua, Indonesia. Oxalidaceae family has over 900 species separated into seven genera, Averrhoa, Dapania, Biophytum, Eichleria, Hypseocharis, Oxalis, and Sarcotheca (Muharini et al., 2014). Out of the 80 species, only several species are known to have medicinal properties for their bioactive compounds, which are B. petersianum, B. umbraculum, B. sensitivum (L.) DC (Inngjerdingen et al., 2008), B. veldkampii, and $B$. reinwardtii.

Kebar grass (KG) extract has been reported to have a bioactive compound with its antifungal and antiaflatoxin (Lisangan et al., 2014), antimalaria, wound healing, stomach ache drug and kidney stone (Inngjerdingen et al., 2008) and antioxidant activity (Pham et al., 2013; Aminudin et al., 2020). In Mali, a plant similar to B. petersianum Klotzsch. is B. umbraculum Welw. for having the same morphological structure (Pham et al., 2013). Scientifically KG claim to be a medicinal plant supported by the presence of a certain compound with antioxidant activity has never been reported. Thus, to answer the claim several scientific studies should be performed to determine the specific bioactive compounds contained in KG with antioxidant activity. One of the methods to gain information on unknown specific bioactive compounds in a plant is by metabolomic approach.
In next future, the discovery of specific bioactive compounds in $\mathrm{KG}$ has the opportunity to become a source of functional food ingredients or supplement as an antioxidant agent to improve reproductive health and performance. The trend in the novel functional food ingredient is functional foods help in the promotion of optimal health conditions such as antioxidants, polyunsaturated fatty acids (PUFAs), and probiotics/prebiotics/ synbiotics (Granato et al., 2020).

Metabolomic is a relatively new analysis method with support holistic approach designed to overcome the obstacles of biological product research (Yuliana et al., 2011) in analyzing the composition of bioactive compounds contained in the cell, tissue, or organism comprehensively and quantitatively (Dettmer et al., 2007; Tugizimana et al., 2019) as well as able to detect untargeted compounds (Sévin et al., 2015) and also targeted compounds (Blasco et al., 2015). Research with metabolomic approach produces multidimensional data (wavelength, retention time, and compound concentration) obtained from extract or fraction and thus multivariate data statistical analysis (MVD) is required. Orthogonal projection to latent structure (OPLS) analysis is one of MVD analyses which is widely used in metabolomics research, which within it studied the correlation between the bioactive chemical profile and the bioactivity of plant extract (Yuliana et al., 2011). Thus, this aim of this study is to identify 
the specific bioactive compounds of Kebar grass extract with the high antioxidant ability and assumed to have an active role as functional compounds with medicinal properties by using a metabolomic approach.

\section{Materials and methods}

\subsection{Ingredients, chemicals, and reagents}

The main ingredients used were Kebar grass. Chemicals such as methanol, hexane, chloroform, ethyl acetate, formic acid, acetonitrile were obtained from Merck, Darmstadt, Germany. Reagents such as Trolox (6-Hydroxy-2,5,7,8-tetramethylchromane2-carboxylic acid), ascorbic acid, and DPPH (2,2-diphenyl-1picrylhydrazyl) were obtained from Sigma-Aldrich (St. Louis, MO, USA).

\subsection{Sample preparation}

Sample preparation was performed according to Andarwulan et al. (2012) with drying modification by using sunlight. Dry sample was ground and sieved with 30 mesh, and then packed (@25 g/package) and stored in freezer $\left(-20^{\circ} \mathrm{C}\right)$ until analyzed.

\subsection{Extraction}

KG extraction was performed conventionally (local wisdom) by boiling $30 \mathrm{~g}$ of dry KG with $600 \mathrm{~mL}$ of water. Extraction modification was performed to maximized extract collection which was by sonication, centrifugation, and filtration with Whatman No. 42 paper and have its pulp reextracted (Aminudin et al., 2020). Extraction was carried out six replications. Final extract was concentrated with rotary evaporator and dried with $\mathrm{N}_{2}$ gas to obtain KG fine powder (CE). CE yield was calculated (Equation 1).

CE yield $(\%)=\frac{C E \text { weight }(g)}{K G \text { powder weight }(g)} \times 100 \%$

\subsection{Fractionation}

Fractionation was performed by graduated liquid-liquid fractionation method by three organic solvents with an order began from hexane, chloroform and ethyl acetate. As much as $9 \mathrm{~g} \mathrm{CE}$ mixed with $225 \mathrm{~mL}$ distilled water, mixed and sonicated for 30 minutes. First fractionation was by hexane. The procedure was by putting mixture $(9 \mathrm{~g} \mathrm{CE}+225 \mathrm{~mL}$ distilled water $)$ into separating funnel, adding $225 \mathrm{~mL}$ hexane, mixing for 5 minutes, and then leaving the mixture until separation of the polar phase and non-polar phase were present. Nonpolar hexane diluted fraction was separated and contained in dark glass bottle. Meanwhile, the polar fraction was added with $225 \mathrm{~mL}$ hexane for another fractionation just like the previous step. Fractionation process was proceeded with chloroform and finally with ethyl acetate. The last fractionation was obtained was ethyl acetate and water fraction. Fraction results were hexane fraction (FH), chloroform fraction (FC), ethyl acetate fraction (FEA) and water fraction (FW). The fractionation was carried out six times in order to obtaine six samples from every fraction. Extract from every fraction was then concentrated and dried with the same method as CE extraction. The yield from fractionation was calculated (Equation 2).

Fraction yield $(\%)=\frac{\text { fraction extract weight }(g)}{\text { CE weight }(g)} \times 100 \%$

\subsection{Antioxidant activity assay by DPPH method}

Antioxidant activity assay was performed according to a method by Iqbal et al. (2015) with few modifications. DPPH reagent (in methanol, $0.8 \mathrm{mM}$ ) was mixed with extract/fraction/ standard (in methanol) with the ratio $1: 1(\mathrm{v} / \mathrm{v})$. The mixture was then poured into assay tube and vortexed for 10 second then incubated for 30 minutes in a dark place on ambient temperature. Absorbance of the mixture was measured in $517 \mathrm{~nm}$ wavelength by using spectrophotometer. Ascorbic acid and Trolox standard were measured in a concentration of $0.391-25.0 \mathrm{mg} / \mathrm{L}$. Samples were tested six replications. Regression curve was obtained from standard inhibition value conversed from their absorbance value. This standard curve was used to determine sample antioxidant activity (extract/fraction). The activity unit of sample antioxidant was called as ascorbic acid equivalent (mgAE/gDW, milligram ascorbic acid equivalent per gram dry weight) and Trolox equivalent (mgTE/gDW, milligram Trolox equivalent per gram dry weight). The sample inhibition value against $\mathrm{DPPH}$ radicals was obtained by measuring control absorbance (Ao) and sample/standard absorbance (As). Inhibition value was calculated (Equation 3).

$\%$ inhibition power $=\frac{\left(A_{o}-A_{s}\right)}{A_{o}} \times 100 \%$

The $\mathrm{IC}_{50}$ value was counted by regression equation interpolation. Regression equation was obtained by the correlation of every sample concentration against its inhibition percentage. The antioxidant inhibition ability was divided into four categories, $0 \%$ to $20 \%$ (low), $20 \%$ to $40 \%$ (moderate), $40 \%$ to $80 \%$ (good) and $80 \%$ to $100 \%$ (very good) (Nahak et al., 2014).

\subsection{Extract/fraction specific bioactive chemical profile by HPLC}

Analysis of specific bioactive chemical profiles used HPLC instrument (HPLC Agilent Technologies, Multi Wavelength Detektor (MWD) with C18 column $(5 \mu \mathrm{m}, 150 \mathrm{x}$ $4.6 \mathrm{~mm})$ ). The chemical profile analysis of specific bioactive compounds by HPLC followed (Andarwulan et al., 2010) and (Maser et al., 2015) with few modifications. Samples (CE, FH, FC, FEA and FW) in $0.8 \mu \mathrm{g} / \mathrm{mL}$ concentration in methanol were filtered by regenerated membrane $0.45 \mu \mathrm{m}$. The autosampler injection volume $40 \mu \mathrm{L}$ filtrate from every sample was injected by HPLC and measured in 6 wavelength variations, which were $250 \mathrm{~nm}, 270 \mathrm{~nm}, 290 \mathrm{~nm}, 310 \mathrm{~nm}, 330$ $\mathrm{nm}$, and $350 \mathrm{~nm}$. HPLC was operated in room temperature with flow rate $1 \mathrm{~mL} \mathrm{~min}{ }^{-1}$. The elution was performed in a gradient within $20 \mathrm{~min}$. The HPLC mobile phase consisted of acetic acid solution $0.1 \%(\mathrm{~A})$ and acetonitrile (B). For B elution gradient $2-5 \% \mathrm{~B}$ (3 $\mathrm{min}), 5-15 \% \mathrm{~B}$ (7 $\mathrm{min}), 15-30 \%$ $\mathrm{B}(6 \mathrm{~min})$, and $30-2 \% \mathrm{~B}$ (4 min). Data collected from HPLC 
result chromatogram were retention time $(\mathrm{RT}, \mathrm{min})$ and curve area $\left(\mathrm{mAU}^{\star} \mathrm{s}\right.$ or absorbance $\mathrm{mL}$ unit ${ }^{*}$ time gap). This HPLC data was used as the chemical profile to be used in metabolomic analysis with OPLS model.

\subsection{Data processing by metabolomic}

The initial step before data processing with metabolomic was by defining the metabolomic canonical model as illustrated by Worley \& Powers (2013) with few modifications. The X matrix was the sample chemical profile information data and Y Matrix was the response data of $\mathrm{IC}_{50}$ value. The number of sample unit was 180 sample units obtained from five samples extract/fraction (CE, FH, FC, FEA, FW) x 6 repetitions $\mathrm{x} 6$ wavelengths. The chemical profile was obtained from the HPLC chromatogram as explained above in the sample chemical profile analysis with HPLC.

Metabolomic data processing began with correlating $\mathrm{X}$ Matrix and Y matrix with OPLS method by using SIMCA software (Simca 14.1, Umetrics, Umea, Sweden). Before the data was processed with OPLS, X Matrix and Y matrix was pre-processed to avoid data overlap. The pre-processing method used was scaling and transformation. Data scaling method with Pareto (Par) was continued by transformation using auto transform selected as appropriate $(10 \log (\mathrm{C} 1$ * $\mathrm{X}+\mathrm{C} 2)$ ).

After data were preprocessed, it was then followed by metabolomic analysis by using the OPLS method. OPLS method was used to evaluate the relationship between $\mathrm{X}$ Matrix and Y Matrix and obtaining one important variable for X Matrix which correlated with Y Matrix. OPLS analysis model was considered to be have good quantitative and prediction performance if $R^{2} Y \geq 0.65$ and $Q^{2} Y \geq 0.50$ (Eriksson et al., 2013; Mabuchi et al., 2019). The validity of the OPLS model chosen sample was assessed by CV-Score vale and accurate assessment of the OPLS model was performed by permutation test.

OPLS analysis model which had been used in this research was score scatter plot and score plot (S-plot). The score scatter plot separated sample (X Matrix) based on the antioxidant activity (Matrix Y) to obtain active samples and inactive samples. Score plot produced sample separation based on quadrants and thus certain sample with certain score would be separated well with value criteria of $\mid p$ (corr) $\mid>0.50$ (Black et al., 2017). The quadrant identified for antioxidant activity $\left(\mathrm{IC}_{50}\right)$ was quadrant three. From two attributes of the OPLS model criteria analysis, one sample assumed to be the most dominant in antioxidant activity would be obtained.

A sample from the OPLS model criteria analysis was then validated with a CV-Score plot. CV-scores plot tested if the score plot sample result had good separation compared to other samples. The best CV-score plot criteria were if the absolute validation cross value ( $|\mathrm{tcv}|)$ was the highest (Black et al., 2017). Plot $\mathrm{X}$ observation was used to assay one sample from score plot sample by evaluating the score position in the sample which had significant antioxidant activity (Black et al., 2017).

\subsection{Sample identification with bioactive chemical profile with the highest antioxidant activity by the metabolomic approach}

One sample chosen based on OPLS analysis result was isolated to obtain sample spots based on its specific bioactive compounds separation. Samples were isolated by thin layer chromatography (TLC). TLC procedure followed Gogoi et al. (2015) with few modifications on the mobile phase. The mobile phase eluent was chloroform. Isolated spots were then scraped, diluted with its fraction diluent, centrifuged, and filtrated. The filtrate from every spot was dried by steaming the diluent using $\mathrm{N}_{2}$ gas.

The spots of TLC from isolated results were identified by using UHPLC-MS/MS tandem mass spectrometer (UHPLC Vanquish Tandem Q Exactive Plus Orbitrap HRMS ThermoScientific, column Accucore phenyl hexyl, $100 \times 2.1 \mathrm{~mm}, 2.6 \mu \mathrm{m})$. The principle of UHPLC-MS/MS refers to Yulianto et al. (2017) and Maser et al. (2015). Spots extract were diluted with $100 \mu \mathrm{L}$ methanol and then filtrated by filter membrane $0.45 \mu \mathrm{m}$. The autosampler injection volume $5 \mu \mathrm{L}$ was applied with the temperature of the autosampler at $40{ }^{\circ} \mathrm{C}$ and a flow rate of $0.2 \mathrm{~mL} \mathrm{~min}^{-1}$. Mobile phase consisted of $\mathrm{H}_{2} \mathrm{O}+0.1 \%$ formic acid (A) and acetonitrile $+0.1 \%$ formic acid (B). For $B$ elution gradients were $0.0-1.7 \mathrm{~min}$ (30-40\% B), 1.7-7.0 min (40-75\% B), 7.0-7.8 min (75-100\% B), 7.8-8.2 min (100-30\% B), 8.2-13.0 min (30\% B). Elution was performed for $13 \mathrm{~min}$ with electrospray ionization (ESI) mode positive and negative with mass spectra were obtained profile mode within the $\mathrm{m} / \mathrm{z} 100$ to 1500 range.

UHPLC-MS/MS preprocessing datasets were performed by using software of the MZmine 2.53 version. Before preprocessing, RAW data was divided into two data clusters based on ionization mode (positive and negative mode) by using the Mass Convert instrument from ProteoWizard 3.0. Feature list data $(\mathrm{m} / \mathrm{z}$, retention time, peak area) were then exported to a CSV file. Data processing by MZmine consists of: peak detection, chromatogram deconvolution, deisotoping, filtering, alignment, and gap-filling (Macintyre et al., 2014).

Determination of identified specific bioactive compound types was performed by evaluating chromatogram of MS/MS spectra. The sample peak chromatograms with a significant area were identified for its retention time and then identified for a putative compound according to online databases connected with MZmine software. Various online databases are used such as KEGG, LipidMaps, Pubchem, and MassBank of North America. Bioactive compounds that had been identified were then confirmed by literature.

\subsection{Data analysis}

Data of extract, fractionation, antioxidant assay, and $\mathrm{IC}_{50}$ value were presented in mean value \pm standard deviation (mean \pm SD). Statistical analysis used IBM SPSS Statistics for Windows, version 22 (IBM Corp., Armonk, NY., USA). The comparison between treatment was analyzed by one-way ANOVA followed by Duncan's test on $\mathrm{p}<0.05$. 


\section{Results and discussion}

\subsection{Extraction and fractionation}

KG extraction with conventional method produced crude extract (CE) $5.5 \pm 0.3 \mathrm{~g}$ with a yield of $18.32 \pm 0.01 \%$. Fractionation of $9 \mathrm{~g} \mathrm{CE}$ produced four fractions with a fraction total of $7.28 \pm 0.92 \mathrm{~g}$. The highest yield was from the FW fraction with $64.61 \pm 1.20 \%$, diikuti fraksi FC $(11.96 \pm 0.56 \%)$, fraksi FEA $(2.69 \pm 0.03 \%)$, and $\mathrm{FH}$ fraction $(1.67 \pm 0.09 \%)$.

\subsection{Antioxidant activity}

Antioxidant activity assay results are showed in the CE, the antioxidant activity was within good the category (inhibition power $>40 \%$ ). The antioxidant result of CE showed that the extract from the conventional method can provide relatively high antioxidant activity. For antioxidant assay of fractionation sample, it could be seen that FEA (inhibition power $88.40 \pm 0.69 \%$ ) has the highest antioxidant activity compared to other samples.

Antioxidant activity assay result with $\mathrm{IC}_{50}$ value was showed the lowest $\mathrm{IC}_{50}$ value was FEA; while the highest $\mathrm{IC}_{50}$ was FW. The low $\mathrm{IC}_{50}$ value showed the highest antioxidant activity. Thus, the FEA is very effective as samples with the highest antioxidant properties from Kebar grass. CE sample as the result of conventional method extraction also can provide relatively good antioxidant activity. The antioxidant activity in descending order goes as follow FEA $>\mathrm{CE}>\mathrm{FC}>\mathrm{FH}>\mathrm{FW}$.

\subsection{Sample identification with bioactive compounds with the highest antioxidant activity by the metabolomic approach}

HPLC chemical profile data were divided into 799 retentions times (RT). Thus, the canonical metabolomic model with the OPLS method was built by correlating 180 sample units (five extract/fraction samples x 6 repetitions x 6 wavelengths) in which contained a chemical profile of 799 retention times (as $\mathrm{X}$ matrix) with one $\mathrm{IC}_{50}$ value (Y Matrix). The datasets build out of OPLS formulation were 800 datasets (799 RT data and one $\mathrm{IC}_{50}$ data). The purpose of metabolomic with OPLS method was to obtain one variable (sample unit) from X Matrix with the highest dominant antioxidant activity.

The initial phase of the metabolomic process was to observe the separation (discrimination) between sample units or variables based on its antioxidant activities. Variable discrimination was required to separate active samples (variables which correlate with antioxidant activity) and inactive samples (variables which do not or lack correlation with antioxidant activity). OPLS variable discrimination should show good Matrix X variables as an interpretation of antioxidant activity (Matrix Y). Variable discrimination in OPLS was performed by using the score scatterplot attribute. A good discrimination was determined by at least one variable has S-plot correlation coefficient $(\mid p($ corr $) \mid)>0.50$ with S-plot significant value $(|\mathrm{p}|)>0.03$ ) (Black et al., 2017) and with value of model criteria $\mathrm{R}^{2} \mathrm{Y}>0.50$ and prediction $\mathrm{Q}^{2} \mathrm{Y}>0.4$ (Mehmood et al., 2012; Blasco et al., 2015; Alexander et al., 2015; Rivero-Cruz et al., 2017). In autofitted components separation $2+1+0$, the highest $S$-plot value variable was $(\mid \mathrm{p}($ corr $) \mid)=0.454$, with S-plot significance value of $(|p|)=0.00$ and $R^{2} Y$ value $=0.957$ and prediction value $\mathrm{Q}^{2} \mathrm{Y}=0.596$. Components separation with autofitted $1+1+0$ obtained variable with the highest S-plot $(\mid \mathrm{p}($ corr $) \mid)=0.519$, and S-plot significance $(|\mathrm{p}|)=0.00$ and $\mathrm{R}^{2} \mathrm{Y}=0.895$ and prediction $\mathrm{Q}^{2} \mathrm{Y}=0.572$.

Based on the requirement of at least one variable with discrimination value according to the above criteria (Figure 1a), the one which fulfilled the criteria was autofitted $1+1+0$ components because S-plot value being (shown by black arrow mark in Figure 1b) $(\mid \mathrm{p}($ corr $) \mid)=0.519>0.50$ (Black et al., 2017). The variable with $S$-plot value $(\mid \mathrm{p}$ (corr) $\mid)=0.519$ (Figure $1 \mathrm{~b})$, was then identified further with XVar-plot and the obtained was variable 80 (Var_80) which then identified to be in ethyl acetate in the third repetition samples (FEA3) with $330 \mathrm{~nm}$ wavelength (FEA3_330). Var_80 in FEA3_330 was identified by XObs-plot to acquire the highest peak chemical profile as the peak that most contributed to antioxidant activity. Based on the XObs-plot, the highest peak chemical profile identification result of var- 80 was in FEA3_330. The highest is assumed to be the observation variable positon in sample FEA3_330 which is strongly assumed to be the most significant one sample unit in antioxidant activity.
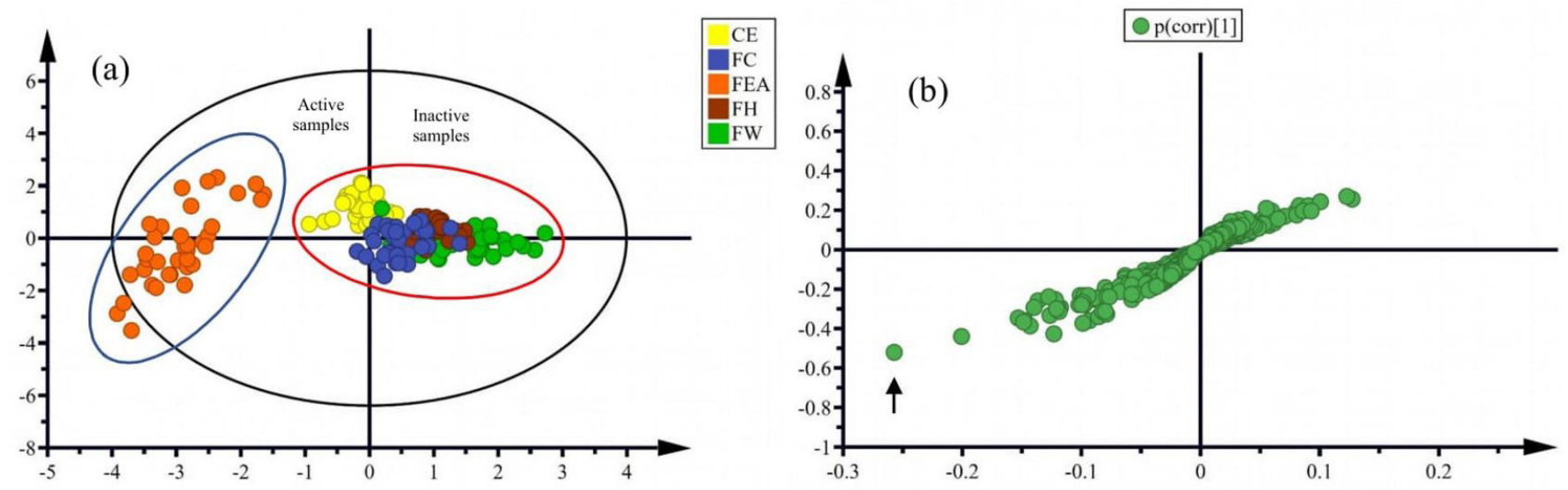

Figure 1. Discrimination plot of autofitted $1+1+0$ components. (a) Discrimination of the variable score scatter plot's attribute obtained by the value of $\mathrm{R}^{2} \mathrm{Y}=0.895$ and the prediction of $\mathrm{Q}^{2} \mathrm{Y}=0.572$; (b) Identification of S-plot's attribute, there is one variable with S-plot value $(\mid p($ corr $) \mid)=0.519$ (shown by black arrow mark) with S-plot significance $(|\mathrm{p}|)=0.00$. 
Based on the OPLS analysis with S-plot, sample FEA3 330 was determined as the chosen sample (shown by arrow mark on Figure $1 \mathrm{~b}$ ). To validate the S-plot result CV-score was performed. Absolute CV-score value (tcv) in sample FEA3_330 was 2.94. This tcv value of 2.94 is the highest tcv value among all samples, which confirmed the S-plot analysis. The criteria of the best CV-score value is if it has the highest cross-validation absolute value ( $|\mathrm{tcv}|)$ out of all samples (Black et al., 2017). The following validation is a permutation test to determine that the OPLS model was the one which resulted from sample FEA3_330. The permutation test was performed randomly. In this study, 200 datasets $(n=200)$ were used from 800 datasets that were performed in this OPLS method. Permutation test results could be observed in Figure 2. The permutation test $(n=200)$ resulted intercept $R^{2} Y=0.729$ and intercept $\mathrm{Q}^{2} \mathrm{Y}=-0.288$. This permutation test is determined to be the a good category because the intercept values were under value of the $\mathrm{R}^{2} \mathrm{Y}$ model $(=0.895)$ and $\mathrm{Q}^{2} \mathrm{Y}$ prediction $(=0.572)$ (see in Figure 1a). According to Mabuchi et al. (2019) the permutation test response is deemed as good if the intercept value of the permutation test result was under the OPLS model and prediction intercepts.

Based on the analysis result and OPLS model validation as explained above, the chosen sample FEA3_330 is the sample assumed to contribute the most in antioxidant activity. This FEA3 sample was then isolated and analyzed to have its specific bioactive compounds be identified.

\subsection{Identfication of specific bioactive compounds of the OPLS result chosen sample with the highest antioxidant activity}

Chosen sample (FEA3) was isolated by using TLC. TLC analysis result of sample FEA3 resulted in four spots which were named Spot 1, Spot 2, Spot 3, and Spot 4. Four spots of TLC were analyzed by using UHPLC-MS/MS in ESI (+) and ESI (-) to obtain eight chromatograms. From the evaluation of every chromatogram, ten dominant peaks detected were assumed as specific bioactive compounds (Table 1). From ten bioactive compounds, two of them were identified, while eight others were still yet to be identified. The Spot 1 identification detected six peaks (Figure 3), namely three peaks from ESI $(+)$ and three peaks from ESI (-). On ESI (+) Spot 1 (Figure 3a), one peak is identified as cassioaccidentalin A and two peaks are unknown. On ESI (-) Spot 1 (Figure 3b), two peaks were identified as cassioaccidentalin A and as caffeic acid and one peak was unknown. Spot 2 and Spot 3 were detected only on ESI (+), each of which has one peak. The last, Spot 4 is detected in both ESI (+) and ESI (-) and has two peaks. Of all the peaks detected on Spots 2, 3, and 4 the names of the compounds have not been identified or unknown (see Table 1).

The identification of caffeic acid (CA) (Figure 3b) was obtained from the KEGG online database after previously being processed with MZmine software. The CA identification result showed spectrum signal in RT 1.74, had m/z 179.03421 $[\mathrm{M}-\mathrm{H}]^{-1}, \mathrm{~m} / \mathrm{z} 293.028$ [M-H+TFA $^{-1}$, and molecular weight $180.0415 \mathrm{~g} / \mathrm{mol}$. CA identification on this study result is similar to CA from methanol and water extract of Zuccagnia punctate which obtained m/z 179.0350 (Solorzano et al., 2019). CA molecular structure is $\mathrm{C}_{9} \mathrm{H}_{8} \mathrm{O}_{4}$. CA is included as phenolic acid group with anti-inflammatory (Genaro-Mattos et al., 2015; Espíndola et al., 2019), anti-mutagenic (Genaro-Mattos et al., 2015), anti cancer (Espíndola et al., 2019), and anti-carcinogenic activity and anti-bacterial (Genaro-Mattos et al., 2015). The pharmacological properties of CA is related to the antioxidant activity it has (Genaro-Mattos et al., 2015; Espíndola et al., 2019; Gülçin, 2006). CA antioxidant activity is probably because by its molecular structure there are benzene ring, carboxylic acid, hydroxyl, and methoxyl group, with carbon chain double bond (Espíndola et al., 2019; Magnani et al., 2014). CA could celate metal, prevent the formation of hydroxyl radical, and inhibit

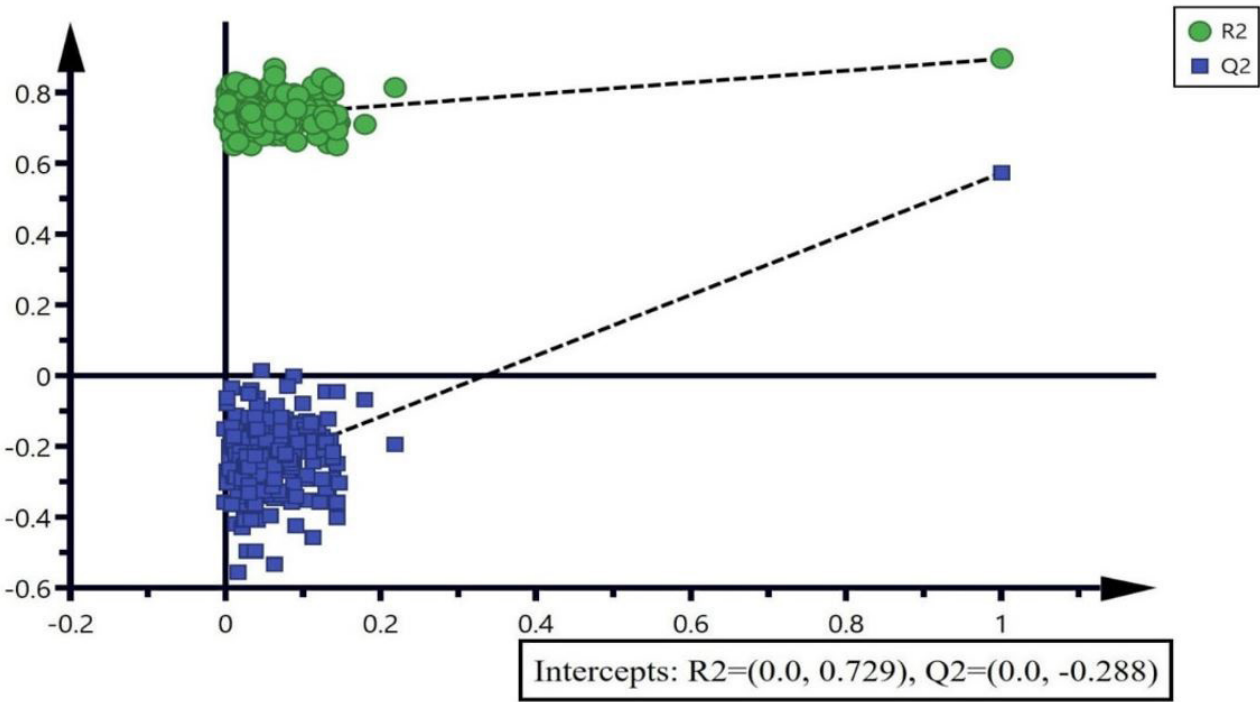

Figure 2. Permutation test of 200 datasets $(n=200)$ from 800 datasets that performed in this OPLS method. The permutation test $(n=200)$ resulted $R^{2} Y=0.729$ and $Q^{2} Y=-0.288$ intercepts. This permutation test is deemed good because the intercept values were below the intercept of the $\mathrm{R}^{2} \mathrm{Y}$ model (=0.895) and $\mathrm{Q}^{2} \mathrm{Y}$ prediction (= 0.572) (Mabuchi et al., 2019). 
Table 1. Identification of bioactive compounds from four TLC spots by UHPLC-MS/MS compared with the reference.

\begin{tabular}{|c|c|c|c|c|c|c|c|c|}
\hline No & Spot/RT & $\begin{array}{l}\text { Ionization type } \\
\text { (ESI) }\end{array}$ & $\begin{array}{l}\text { Mass of } \\
\text { feature } \\
(\mathrm{m} / \mathrm{z})\end{array}$ & $\begin{array}{l}\text { Exact } \\
\text { mass } \\
(\mathrm{m} / \mathrm{z})\end{array}$ & Compound $^{1}$ & $\begin{array}{l}\text { Molecular } \\
\text { formula }\end{array}$ & Class compound & Referensi \\
\hline \multicolumn{9}{|c|}{ Spot 1} \\
\hline 1 & 1.57 & {$[\mathrm{M}+\mathrm{H}]^{+1}$} & 227.1747 & 226.1747 & unknown & - & - & - \\
\hline 2 & 1.58 & {$[\mathrm{M}-\mathrm{H}]^{-1}$} & 128.034 & 129.012 & unknown & - & - & - \\
\hline 3 & 1.74 & {$[\mathrm{M}-\mathrm{H}]^{-1}$} & 179.0344 & 180.160 & Caffeic acid & $\mathrm{C}_{9} \mathrm{H}_{8} \mathrm{O}_{4}$ & Carboxylic acid & $\begin{array}{c}\text { KEGG }(2020)^{2)} \text {; } \\
\text { Solorzano et al. }(2019)\end{array}$ \\
\hline 4 & 1.76 & {$[\mathrm{M}+\mathrm{H}]^{+1}$} & 126.0912 & 125.0912 & unknown & - & - & - \\
\hline 5 & 1.95 & $\begin{array}{c}{[\mathrm{M}+\mathrm{H}]^{+1}} \\
{[\mathrm{M}+\mathrm{Na}-\mathrm{H}]^{+1}} \\
{\left[\mathrm{M}+\mathrm{NH}_{3}\right]^{+1}}\end{array}$ & $\begin{array}{r}561.1593 \\
583.1403 \\
1138.3341\end{array}$ & 560.1530 & Cassiaoccidentalin A & $\mathrm{C}_{27} \mathrm{H}_{28} \mathrm{O}_{13}$ & Flavonoids & $\begin{array}{c}\text { LipidMaps }(2020)^{3)} ; \\
\text { Hatano et al. }(1997) \\
\text { Nono et al. }(2016)\end{array}$ \\
\hline 6 & 1.97 & {$[\mathrm{M}-\mathrm{H}]^{-1}$} & 559.1462 & 560.1530 & Cassiaoccidentalin A & $\mathrm{C}_{27} \mathrm{H}_{28} \mathrm{O}_{13}$ & Flavonoids & $\begin{array}{l}\text { LipidMaps }(2020)^{3} \text {; Hatano et al. } \\
(1997) \text {; Nono et al. (2016) }\end{array}$ \\
\hline \multicolumn{9}{|c|}{ Spot 2} \\
\hline 7 & 1.06 & $\begin{array}{c}{[\mathrm{M}+\mathrm{H}]^{+1}} \\
{[\mathrm{M}+\mathrm{ACN}+\mathrm{H}]^{+1}}\end{array}$ & $\begin{array}{l}177.007 \\
218.033 \\
\end{array}$ & 175.999 & Unknown & - & - & - \\
\hline \multicolumn{9}{|c|}{ Spot 3} \\
\hline 8 & 1.02 & {$[\mathrm{M}+\mathrm{H}]^{+1}$} & 174.999 & 173.992 & Unknown & - & - & - \\
\hline \multicolumn{9}{|c|}{ Spot 4} \\
\hline 9 & 1.06 & {$[\mathrm{M}-\mathrm{H}]^{-1}$} & 248.900 & 249.907 & Unknown & - & - & - \\
\hline 10 & 2.23 & {$[\mathrm{M}+\mathrm{H}]^{+1}$} & 123.0358 & 122.0358 & Unknown & - & - & - \\
\hline
\end{tabular}

${ }^{1}$ Putative identification using Mzmine software from MS/MS data (UHPLC Vanquish Tandem Q Exactive Plus Orbitrap HRMS ThermoScientific). The online database is used for the identification of compounds such as KEGG, PubChem, LipidMaps, and MassBank of North America. The identification results of the compounds found were then confirmed by the literature; ${ }^{2}$ Identification using online The KEGG COMPOUND: C01197 (KEGG, 2020 ); ${ }^{3}$ Identification using The LIPID MAPS ${ }^{\bullet}$ Lipidomics Gateway (LipidMaps, 2020).

lipid membrane peroxidation (Genaro-Mattos et al., 2015; Gülçin, 2006).

As antioxidant agent. CA can react with free radicals and can prevent over reactive oxygen species (ROS), and depleting tumor cell angiogenesis as well as blocking and suppressing factors which trigger hepatocarcinoma (Espíndola et al., 2019). ROS may be in the form of radical ROS such as superoxide anion radical $\left(\mathrm{O}_{2}^{*}\right)$, hydroxyl radikal $\left(\mathrm{OH}^{-}\right)$, and non-radical ROS such as hydrogen peroxide $\left(\mathrm{H}_{2} \mathrm{O}_{2}\right)$, and singlet oksigen $\left({ }^{1} \mathrm{O}_{2}\right)$ (Espíndola et al., 2019; Magnani et al., 2014). Known CA sources are vegetables, fruits, olive, coffee, potatoes, carrot, propolis (Genaro-Mattos et al., 2015; Espíndola et al., 2019), basil, and several plants from the genus Salvia (Hao et al., 2015). By the identification of CA compound in Kebar grass, a novel source of CA is identified.

Identification of the cassiaoccidentalin A (CsA) (Figure 3a, 3b) was obtained from the online database LipidMaps after previously being processed with MZmine software. CsA is identified in ESI (+) and ESI (-) mode. On ESI (+) mode (Figure 3a), CsA is identified on the spectrum signal on RT 1.95 with $\mathrm{m} / \mathrm{z} 561.1593$ $[\mathrm{M}+\mathrm{H}]^{+1}, \mathrm{~m} / \mathrm{z} 583.1403[\mathrm{M}+\mathrm{Na}-\mathrm{H}]^{+1}, \mathrm{~m} / \mathrm{z} 1138.3341\left[\mathrm{M}+\mathrm{NH}_{3}\right]^{+1}$, and the molecular weight (exact mass) is $560.153 \mathrm{~g} / \mathrm{mol}$. On ESI (-) mode (Figure 3b), CsA was identified on the spectrum signal on RT 1.97 with $\mathrm{m} / \mathrm{z} 559.1462[\mathrm{M}-\mathrm{H}]^{-1}$, and molecular weight (exact mass) $560.153 \mathrm{~g} / \mathrm{mol}$.

There are three types of cassiaoccidentalin (Cs) compound, which are CsA, CsB, and CsC (Hatano et al., 1997). The three types of cassiaoccidentalin were isolated from ethyl acetate extract of Cassia occidentalis plants (Hatano et al., 1997). Specifically, Hatano et al. (1997), identified CsA compound from Cassia occidentalis plant by using NMR-ESI/MS instrument and obtained $\mathrm{m} / \mathrm{z}$ value of $561[\mathrm{M}+\mathrm{H}]^{+1}$ with molecular equation $\mathrm{C}_{27} \mathrm{H}_{28} \mathrm{O}_{13}$ and detected in maximum UV absorbance of 215, 271, and $336 \mathrm{~nm}$. CsA molecular structure comprised of three parts (Figure 4) which are (1) aglycone structure $\left(\mathrm{C}_{15} \mathrm{H}_{9} \mathrm{O}_{5}\right)$, (2) 6-Deoxy-ribohexos-3-ulose structure $\left(\mathrm{C}_{6} \mathrm{H}_{8} \mathrm{O}_{4}\right)$, and (3) rhamnose structure $\left(\mathrm{C}_{6} \mathrm{H}_{11} \mathrm{O}_{4}\right)$ (Hatano et al., 1997). CsA compound identification also has been performed previously by Nono et al. (2016) by isolating methanol fraction of Drymaria cordata which then processed by NMR-ESI/MS instrument and obtaining $\mathrm{m} / \mathrm{z} 584$ $[\mathrm{M}+\mathrm{H}+\mathrm{Na}]^{+1}$, The $\mathrm{m} / \mathrm{z}$ value of $584[\mathrm{M}+\mathrm{H}+\mathrm{Na}]^{+1}$ was identical with cassiaoccidentalin $\mathrm{A}$. Based on the confirmation result from the two CsA identifications in D. cordata (Nono et al., 2016) and in C. occidentalis (Hatano et al., 1997), we could confirm the presence of CsA in Kebar grass plant.

CsA compound is very rarely found in plants. Based on literature review, other than the result of this research and from C. occidentalis and D. cordata. CsA has also been found in ethyl acetate fraction of isolated methanol extract of Biophytum umbraculum reported by Pham et al. (2013). In Biophytum sensitivum, CsA compound has not been found. B. petersianum, $B$ umbraculum, and $B$. sensitivum species have isovitexin and isoorientin compounds, which made the three categorized in the same genus which is Biophytum (Sakthivel \& Guruvayoorappan, 2012). CsA compound is included as flavonoid which has been known for their ability as antioxidant and anti-inflammatory (Pham et al., 2013; Nono et al., 2016) and have lipase-inhibitor 

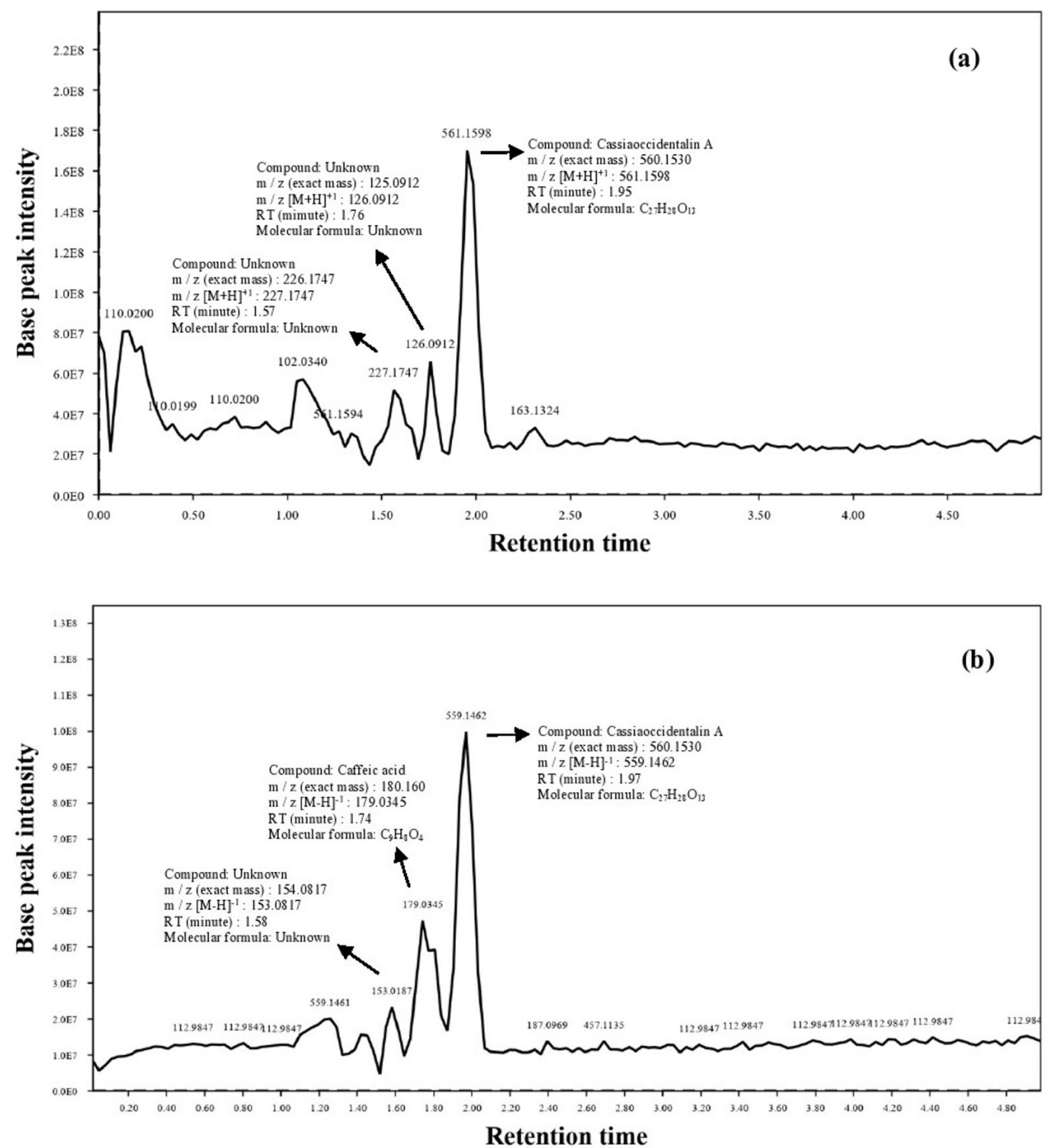

Figure 3. Spot 1 Chromatogram ESI (+) and ESI (-) mode. (a) the result of spot 1 evaluation ESI (+) mode detects 3 peaks that are presumed to be features of the compound, namely (1) at a retention time (RT) of $1.57 \mathrm{~min}, \mathrm{~m} / \mathrm{z} 227.1747[\mathrm{M}+\mathrm{H}]^{+1}, \mathrm{~m} / \mathrm{z} 226.1747$ (exact mass) as an unknown compound, (2) at a retention time (RT) of $1.76 \mathrm{~min}, \mathrm{~m} / \mathrm{z} 126.0912[\mathrm{M}+\mathrm{H}]^{+1}, \mathrm{~m} / \mathrm{z} 125.0912$ (exact mass) as an unknown compound, and (3) at RT $1.96 \mathrm{~min}, \mathrm{~m} / \mathrm{z} 561.1598[\mathrm{M}+\mathrm{H}]^{+1}, \mathrm{~m} / \mathrm{z} 560,1530$ (exact mass) were identified as Cassiaoccidentalin A $\left(\mathrm{C}_{27} \mathrm{H}_{28} \mathrm{O}_{13}\right)$; (b) the result of Spot 1 evaluation ESI (-) mode detects three peaks that are presumed to be features of the compound, namely (1) at a retention time (RT) of 1.58 min, $\mathrm{m} / \mathrm{z} 153.0817[\mathrm{M}-\mathrm{H}]^{-1}, \mathrm{~m} / \mathrm{z} 154.0817$ (exact mass) as an unknown compound, (2) at a retention time (RT) of $1.74 \mathrm{~min}, \mathrm{~m} / \mathrm{z} 179.0345[\mathrm{M}-\mathrm{H}]^{-1}$, $\mathrm{m} / \mathrm{z} 180.160$ (exact mass) which were identified as caffeic acid $\left(\mathrm{C}_{9} \mathrm{H}_{8} \mathrm{O}_{4}\right)$, and (3) at a RT $1.97 \mathrm{~min}, \mathrm{~m} / \mathrm{z} 559,1462[\mathrm{M}-\mathrm{H}]^{-1}, \mathrm{~m} / \mathrm{z} 560.1530(\mathrm{exact}$ mass) which were identified as cassiaoccidentalin $\mathrm{A}\left(\mathrm{C}_{27} \mathrm{H}_{28} \mathrm{O}_{13}\right)$.

activity (Hatano et al., 1997). The antioxidant activity of the CsA compound is associated with the presence of sugar group anomeric carbon bond (aglycone) in atom C-6 or C-8 (Figure 4) which is known to suppress several oxidator species such as anionsuperoxide, hydroxyl, and ferroxyl radical (Zeng et al., 2013). Moreover, antioxidant activity in CsA compound is assumed to be caused by benzene ring, hydroxyl, and methoxyl group and the presence of carbon chain double bond (Magnani et al., 2014; Espíndola et al., 2019).

By the finding of specific bioactive cassiaoccidentalin A in Kebar grass, can be used as a specific marker and strengthen the similarity of Kebar grass (B. petersianum) found in Indonesia with B. umbraculum found in Mali by Pham et al. (2013) for having the same cassiaoccidentalin A compound and has antioxidant activity. In the end, the presence of Cassiaoccidentalin A in Kebar grass proves that this plant has the potential as an antioxidant agent and thus makes the Kebar grass as a potential plant source of functional food ingredients or supplements as antioxidant agents to improve performance and maintain reproductive health in the future. In the future, further research is needed to evaluate the antioxidant effect of herbal drinking supplement composed by KG extract in animal models whose reproductive function is reduced due to exposure to toxic substances to evaluate the recovery of reproductive function 


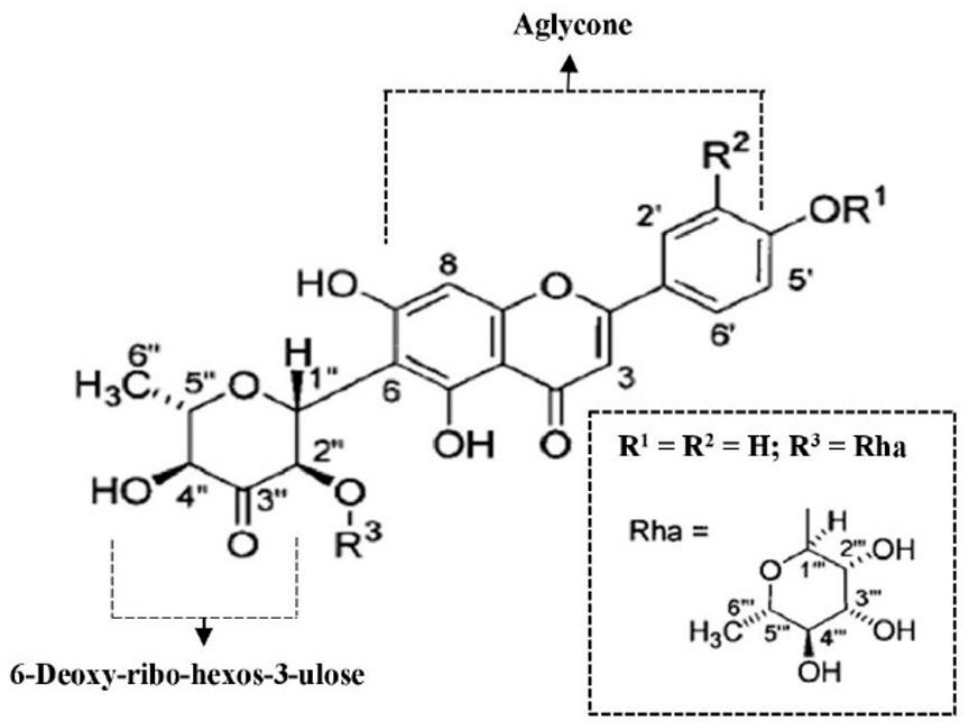

Figure 4. Molecular structure of cassiaoccidentalin $\mathrm{A}\left(\mathrm{C}_{27} \mathrm{H}_{28} \mathrm{O}_{13}\right)$ (Hatano et al., 1997).

of organs or in normal animal models to evaluate the improvement of their organs' reproductive performance.

\section{Conclusion}

Kebar grass conventional extraction method with water (ratio $(\mathrm{b} / \mathrm{v}) 1: 20)$ resulted crude extract (CE) yield $18.32 \pm 0.01 \%$. CE fractionations result obtained yields of $\mathrm{FH}(1.67 \pm 0.09 \%), \mathrm{FC}$ $(11.96 \pm 0.56 \%)$. FEA $(2.69 \pm 0.03 \%)$, and FW (64.61 $\pm 1.20 \%)$. Antioxidant activity was FEA $>\mathrm{CE}>\mathrm{FH}>\mathrm{FC}>\mathrm{FW}$. Metabolomic analysis with OPLS method showed that FEA fraction is the most dominant fraction to contribute to antioxidant activity. Based on the analysis result, in the FEA fraction ten compounds were identified. Two bioactive compounds from the ten bioactive compounds were identified to be caffeic acid and cassiaoccidentalin A. While the rest of the eight bioactive compounds were still unidentified (unknown compound). The finding of cassiaoccidentalin A in Kebar grass is a novel finding and can be used as a specific marker for petersianum species of Biophytum genus. The presence of Cassiaoccidentalin A compound in Kebar grass proves that this plant has the potential as an antioxidant agent and thus makes the Kebar grass as a potential plant source of functional food ingredients or supplements as antioxidant agents to improve performance and maintain reproductive health in the future.

\section{References}

Alexander, D. L., Tropsha, A., \& Winkler, D. A. (2015). Beware of R2: simple, unambiguous assessment of the prediction accuracy of QSAR and QSPR models. Journal of Chemical Information and Modeling, 55(7), 1316-1322. http://dx.doi.org/10.1021/acs.jcim.5b00206. PMid:26099013.

Aminudin, A., Andarwulan, N., Palupi, N. S., \& Arifiantini, I. (2020). Characteristics and antioxidant activity of kebar grass (Biophytum petersianum) extract. Biosaintifika, 12(2), 178-185. http://dx.doi. org/10.15294/biosaintifika.v12i2.23820.

Andarwulan, N., Batari, R., Sandrasari, D. A., Bolling, B., \& Wijaya, H. (2010). Flavonoid content and antioxidant activity of vegetables from Indonesia. Food Chemistry, 121(4), 1231-1235. http://dx.doi. org/10.1016/j.foodchem.2010.01.033. PMid:28814820.

Andarwulan, N., Kurniasih, D., Apriady, R., Rahmat, H., Roto, A., \& Bolling, B. (2012). Polyphenols, carotenoids, and ascorbic acid in underutilized medicinal vegetables. Journal of Functional Foods, 4(1), 339-347. http://dx.doi.org/10.1016/j.jff.2012.01.003.

Black, C., Chevallier, O. P., Haughey, S. A., Balog, J., Stead, S., Pringle, S. D., Riina, M. V., Martucci, F., Acutis, P. L., Morris, M., Nikolopoulos, D. S., Takats, Z., \& Elliott, C. T. (2017). A real time metabolomic profiling approach to detecting fish fraud using rapid evaporative ionisation mass spectrometry. Metabolomics, 13(12), 153. http:// dx.doi.org/10.1007/s11306-017-1291-y. PMid:29151824.

Blasco, H., Blaszczynski, J., Billaut, J. C., Nadal-Desbarats, L., Pradat, P. F., Devos, D., Moreau, C., Andres, C. R., Emond, P., Corcia, P., \& Słowiński, R. (2015). Comparative analysis of targeted metabolomics: dominance-based rough set approach versus orthogonal partial least square-discriminant analysis. Journal of Biomedical Informatics, 53, 291-299. http://dx.doi.org/10.1016/j.jbi.2014.12.001. PMid:25499899.

Dettmer, K., Aronov, P., \& Hammock, B. (2007). Mass spectrometrybased metabolomics. Mass Spectrometry Reviews, 26(1), 51-78. http://dx.doi.org/10.1002/mas.20108. PMid:16921475.

Eriksson, L., Byrne, T., Johansson, E., Trygg, J., \& Vikstrom, C. (2013). Multi- and megavariate data analysis: Basic principles and applications. Malmo Sweden: MKS Umetrics AB.

Espíndola, K., Ferreira, R. G., Narvaez, L., Silva Rosario, A., Silva, A., Silva, A., Vieira, A. P. O., \& Monteiro, M. C. (2019). Chemical and pharmacological aspects of caffeic acid and its activity in hepatocarcinoma. Frontiers in Oncology, 9, 541. http://dx.doi. org/10.3389/fonc.2019.00541. PMid:31293975.

Genaro-Mattos, T. C., Rettori, D., Hermes-Lima, M., Allonso, A., \& Maurício, Â. Q. (2015). Antioxidant activity of caffeic acid against iron-induced free radical generation: a chemical approach. PLoS One, 10(6), e0129963. http://dx.doi.org/10.1371/journal.pone.0129963. PMid:26098639.

Gogoi, J., Nakhuru, K. S., Policegoudra, R. S., Chattopadhyay, P., Rai, A. K., \& Veer, V. (2015). Isolation and characterization of bioactive components from Mirabilis jalapa L. radix. Journal of Traditional and Complementary Medicine, 6(1), 41-47. http://dx.doi.org/10.1016/j. jtcme.2014.11.028. PMid:26870679. 
Granato, D., Barba, F. J., Bursać Kovačević, D., Lorenzo, J. M., Cruz, A. G., \& Putnik, P. (2020). Functional foods: product development, technological trends, efficacy testing, and safety. Annual Review of Food Science and Technology, 11(1), 93-118. http://dx.doi.org/10.1146/ annurev-food-032519-051708. PMid:31905019.

Gülçin, I. (2006). Antioxidant activity of caffeic acid (3, 4-dihydroxycinnamic acid). Toxicology, 217(2-3), 213-220. http://dx.doi.org/10.1016/j. tox.2005.09.011. PMid:16243424.

Hao, D. C., Gu, X. J., Xiao, P. G., Hao, D. C., Gu, X. J., \& Xiao, P. G. (2015). Medicinal plants chemistry, biology and omics. Cambridge: Woodhead Publishing.

Hatano, T., Yamashita, A., Hashimoto, T., Ito, H., Kubo, N., Yoshiyama, M., Shimura, S., Itoh, Y., Okuda, T., \& Yoshida, T. (1997). Flavan dimers with lipase inhibitory activity from Cassia nomame. Phytochemistry, 46(5), 893-900. http://dx.doi.org/10.1016/S0031-9422(97)00367-1.

Inngjerdingen, M., Inngjerdingen, K. T., Patel, T. R., Allen, S., Chen, X., Rolstad, B., Morris, G. A., Harding, S. E., Michaelsen, T. E., Diallo, D., \& Paulsen, B. S. (2008). Pectic polysaccharides from Biophytum petersianum Klotzsch, and their activation of macrophages and dendritic cells. Glycobiology, 18(12), 1074-1084. http://dx.doi. org/10.1093/glycob/cwn090. PMid:18809620.

Iqbal, E., Salim, K. A., \& Lim, L. B. (2015). Phytochemical screening, total phenolics and antioxidant activities of bark and leaf extracts of Goniothalamus velutinus (airy shaw) from Brunei Darussalam. J King Saud Univ-Sci, 27(3), 224-232. http://dx.doi.org/10.1016/j. jksus.2015.02.003.

KEGG. (2020). Retrieved from https://www.kegg.jp/entry/C01197

LipidMaps. (2020). Retrieved from https://www.lipidmaps.org/

Lisangan, M., Rizal, S., Winiati, P., \& Okky, S. (2014). Antifungal activity of Kebar grass (Biophytum petersianum) leaf extracts on the growth of aflatoxigenic aspergillus flavus in food model media. IJSBAR, 24, 179-190.

Macintyre, L., Zhang, T., Viegelmann, C., Martinez, I. J., Cheng, C., Dowdells, C., Abdelmohsen, U. R., Gernert, C., Hentschel, U., \& Edrada-Ebel, R. (2014). Metabolomic tools for secondary metabolite discovery from marine microbial symbionts. Marine Drugs, 12(6), 3416-3448. http://dx.doi.org/10.3390/md12063416. PMid:24905482.

Magnani, C., Isaac, V., Correa, M., \& Salgado, H. (2014). Caffeic acid: a review of its potential use in medications and cosmetics. Analytical Methods, 6(10), 3203-3210. http://dx.doi.org/10.1039/C3AY41807C.

Maser, W. H., Yuliana, N. D., \& Andarwulan, N. (2015). Rapid Identification of Antibacterial Compounds from Turkey berry by HPLC-Based Metabolomics. Journal of Liquid Chromatography \& Related Technologies, 38(12), 1230-1235. http://dx.doi.org/10.1080 /10826076.2015.1032419.

Mehmood, T., Liland, K. H., Snipen, L., \& Sæbø, S. (2012). A review of variable selection methods in partial least squares regression. Chemometrics and Intelligent Laboratory Systems, 118, 62-69. http:// dx.doi.org/10.1016/j.chemolab.2012.07.010.

Mabuchi, R., Tanaka, M., Nakanishi, C., Takatani, N., \& Tanimoto, S. (2019). Analysis of primary komponen bioaktifes in cabbage (Brassica oleracea var. capitata) varieties correlated with antioxidant activity and taste attributes by metabolic profiling. Molecules, 24(23), 4282. http://dx.doi.org/10.3390/molecules24234282.

Muharini, R., Wray, V., Lai, D., \& Proksch, P. (2014). New flavone C-glycosides from leaves of Sarcotheca griffithii (Hook F) Hallier F. Phytochemistry Letters, 9, 26-32. http://dx.doi.org/10.1016/j. phytol.2014.04.005.
Nahak, G., Suar, M., \& Sahu, R. K. (2014). Antioxidant potential and nutritional values of vegetables: a review. Research Journal of Medicinal Plant, 8(2), 50-81. http://dx.doi.org/10.3923/rjmp.2014.50.81.

Nono, R. N., Nguelefack-Mbuyo, E. P., Nzowa, L. K., Ponou, B. K., Teponno, R. B., Nguelefack, T. B., Barboni, L., Tapondjou, L. A., \& Park, H. J. (2016). Antioxidant C-glycosylflavones of Drymaria cordata (Linn.) Willd. Archives of Pharmacal Research, 39(1), 4350. http://dx.doi.org/10.1007/s12272-015-0691-7. PMid:26642770.

Pham, A., Nguyen, C., Malterud, K., Diallo, D., \& Wangensteen, H. (2013). Bioactive Flavone-C-Glycosides of the African medicinal plant Biophytum umbraculum. Molecules, 18(9), 10312-10319. http://dx.doi.org/10.3390/molecules180910312. PMid:24064447.

Rivero-Cruz, J., Rodríguez de San Miguel, E., Robles-Obregón, S., Hernández-Espino, C., Rivero-Cruz, B., Pedraza-Chaverri, J., \& Esturau-Escofet, N. (2017). Prediction of antimicrobial and antioxidant activities of Mexican propolis by $1 \mathrm{H}-\mathrm{NMR}$ pectroscopy and chemometrics data analysis. Molecules, 22(7), 1184. http:// dx.doi.org/10.3390/molecules22071184.

Sakthivel, K. M., \& Guruvayoorappan, C. (2012). Biophytum sensitivum: ancient medicine, modern targets. International Journal of Advanced Research in Pharmaceuticals Bio Sciences, 3(2), 83-91. http://dx.doi. org/10.4103/2231-4040.97279. PMid:22837955.

Sévin, D. C., Kuehne, A., Zamboni, N., \& Sauer, U. (2015). Biological insights through nontargeted metabolomics. Current Opinion in Biotechnology, 34, 1-8. http://dx.doi.org/10.1016/j.copbio.2014.10.001. PMid:25461505.

Solorzano, E. R., Di Gangi, I. M., Roverso, M., Favaro, G., Bogialli, S., \& Pastore, P. (2019). Low level of allergens in the Argentinean plant Zuccagnia punctata Cav.: screening and quality control of NorthWestern Propolis using an LC-DAD-QTOF system. Applied Sciences, 9(17), 3546. http://dx.doi.org/10.3390/app9173546.

Tugizimana, F., Steenkamp, P., Piater, L., Labuschagne, N., \& Dubery, I. A. (2019). Unravelling the metabolic reconfiguration of the post-challenge primed state in sorghum bicolor responding to Colletotrichum sublineolum infection. Metabolites, 9(10), 194. http:// dx.doi.org/10.3390/metabo9100194. PMid:31547091.

Worley, B., \& Powers, R. (2013). Multivariate analysis in metabolomics. Current Metabolomics, 1(1), 92-107. http://dx.doi.org/10.2174/221 3235X11301010092. PMid:26078916.

Yuliana, N., Khatib, A., Verpoorte, R., \& Choi, Y. (2011). Comprehensive extraction method integrated with NMR metabolomics: a new bioactivity screening method for plants, adenosine A1 receptor binding compounds in Orthosiphon stamineus Benth. Analytical Chemistry, 83(17), 6902-6906. http://dx.doi.org/10.1021/ac201458n. PMid:21800886.

Yulianto, W., Andarwulan, N., Giriwono, F. E., \& Pamungkas, J. (2017). Bioactive compounds from Torbangun (Plectranthus amboinicus (Lour.) Spreng) chloroform fraction induce apoptosis in breast cancer (mcf-7 cells) in vitro. Journal of Traditional and Complementary Medicine, 22(1), 36-44.

Zeng, P., Zhang, Y., Pan, C., Jia, Q., Guo, F., Li, Y., Zhu, W., \& Chen, K. (2013). Advances in studying of the pharmacological activities and structure-activity relationships of natural C-glycosylflavonoids. Acta Pharmaceutica Sinica B, 3(3), 54-162. http://dx.doi.org/10.1016/j. apsb.2013.04.004. 